\title{
Historiografia, franquisme i educació
}

\section{Antonio Fco. Canales (Universidad Complutense de Madrid)}

\author{
Eulàlia Collelldemont i Conrad Vilanou (Coords.), \\ Totalitarismos europeos, propaganda y educación. Una \\ historia visual desde los NO-DO. Gijón, Trea, 2020, 399 \\ pàgs. ISBN: 978-84-18105-29-6
}

Aquest volum dona compte de la consolidació d'un grup de recerca que ha vingut explorant amb èxit les possibilitats ofertes per un apropament visual a la història de l'educació. En aquesta ocasió l'objecte d'estudi són els documentals i més concretament els NO-DOs produïts pel règim franquista. Participen en l'obra els membres de l'equip (Anne Bruch, Isabel Carrillo, Raquel Cercós, Eulàlia Collelldemont, Josep Casanovas, Jordi García, Anna Gómez, lan Grosvenor, Iveta Kestere, Núria Padrós, Pilar Prat i Conrad Vilanou) més un grup de especialistes externs com ara Maria Carme Bernal, Antonio Fco. Canales, Pedro Cerejo, Karina Rivas, Xavier Tornafoch, Ferran Sánchez, Isabel Vilafranca i Antonio Viñao. Tots ells composen un memorable fresc de l'educació en els NO-DOS a partir de variats elements i confirmen la seva potencialitat com a font per a la investigació en història de l'educació. No obstant això, més que oferir detalls de cada un dels capítols, interessa a aquesta ressenya subratllar el meritori esforç del grup per inserir la seva recerca en el marc general de la història contemporània i de les qüestions que s'hi debaten. En aquest sentit aquesta obra és una aportació notable historiogràficament per diverses raons.

En primer lloc, el llibre parteix d'una aposta clara per ubicar el règim franquista en un pla internacional, inserint-lo en el marc dels totalitarismes amb Portugal,
Itàlia i també la Unió Soviètica, tasca a què contribueix la presència de destacats investigadors estrangers en el equip. Més enllà de la discussió sobre la capacitat heurística en història del terme totalitarisme d'Hannah Arendt, sembla innegable que existí una notable similitud de mecanismes de control social i d'instruments de socialització en aquest tipus de règim. L'ús dels nous mitjans de comunicació i d'entreteniment com el cinema amb objectius d'adoctrinament polític mostra la centralitat de la propaganda en la modernitat totalitària. Si a més a més, el visionat d'aquests productes es feia obligatori com en el cas del NO-DO, obtenim un mecanisme d'educació popular extremadament poderós. El NO-DO, en definitiva, no fou més que això, un instrument més en la forja de I'home i la dona de la Nova Espanya especialment útil en un país amb importants bosses d'analfabetisme. Aquest endarreriment educatiu d'Espanya, Portugal i, en gran mesura, d'àmplies zones d'Itàlia situa sobre la taula la particularitat dels mitjans de comunicació audiovisuals en aquests països. En aquest sentit, el NO-DO anticipava la televisió: I'audiovisual com el principal mitjà de transmissió de missatges, imatges que diuen $\mathrm{i}$ formen en societats mancades de la tradicional formació escolar.

El llibre no estudia el NO-DO com a instrument propagandístic en general, sinó 
en la seva relació més directa amb l'àmbit educatiu. Els capítols segueixen una estructura lògica des de l'estudi dels espais educatius (infantil, escolar, formació professional agrària, la universitat), els ambients educatius (la ciutat, els campaments juvenils i la naturalesa i les institucions socials) i, finalment, els agents educatius (des de les autoritats fins a la Secció Femenina passant per l'Església). Es tracta, doncs, d'una visió àmplia del franquisme i del seu projecte educatiu que posa l'accent sobre la importància d'estudiar l'educació com un element clau per entendre el règim. Aquest és el segon element que dota el Ilibre de rellevància historiogràfica.

El debat sobre la naturalesa del règim constitueix un exercici obligat, una mena de ritual iniciàtic, per a tot aquell que pretengui formar part del cercle d'estudiosos del franquisme, a l'igual que el debat sobre el feixisme i els règims dictatorials d'entreguerres. Tots dos constitueixen casos paradigmàtics del que Kuhn denominà exemplars. Significativament ambdós exercicis historiogràfics d'iniciació comparteixen la característica d'ignorar l'educació. A través d'ells, el futur especialista incorpora al seu instrumental teòric la idea de què l'educació no constitueix una variable significativa en el seu camp, que no aporta res ni a la caracterització del franquisme ni tampoc a la del feixisme. En oberta contradicció amb el que s'afirma sobre aquests règims, s'entén que l'educació roman aliena a les novetats rupturistes introduïdes en tots les esferes socials, en una realitat paral-lela regida per lleis pròpies. Enfront d'aquesta sorprenent concepció predominant en la historiografia, el llibre que han coordinat Eulàlia Collelldemont i Conrad Vilanou presenta la virtut de situar l'educació com un element clau en la comprensió del franquisme i en la seva comparació amb els règims dictatori- als d'entreguerres. A fi de comptes, si alguna cosa il.lustra l'especificitat del franquisme, aquesta síntesi única i (cal esperar que) irrepetible de tradicionalisme i modernitat, de reacció dotada de moderns mecanismes d'organització política i social, és sense cap dubte l'educació. Resulta difícil imaginar en l'àmbit visual una icona més rellevant que aquest ministre d'educació gairebé perpetu que fou lbáñez Martín, un nacional-catòlic vestit de falangista. La seva imatge és en si mateixa la síntesi, i d'aquí l'ús del terme vestit i no disfressat, perquè no era una utilització instrumental, era molt més: una simbiosi, una lenta precipitació coagulant de tradicionalisme i modernitat. Es tractava d'aqueixa síntesi empírica que va més enllà de la teorització, tan difícil de traduir a l'anglès i de fer comprensible per als estrangers, que, emperò, nosaltres detectem quasi instintivament encara avui en dia.

Finalment, cal esmentar un tercer element historiogràfic que aporta l'estudi de l'educació sota el franquisme: el caràcter radicalment rupturista del règim. Feixista o no, el franquisme suposà un trencament radical amb la tradició espanyola, amb la República, sens dubte, però també amb la monarquia liberal $\mathrm{i}$ amb tot el segle xix. La veritable excepcional espanyola és filla del franquisme. Fou amb el règim, més aviat amb la seva supervivència anacrònica després de la derrota internacional dels feixismes, quan el nostre país es separà realment de l'evolució històrica dels països del seu entorn. El Spain is different que el mateix franquisme proclamava en els seixanta era més aviat un hem fet a Espanya diferent, una reivindicació castissa de la principal realització del règim: desviar Espanya del curs natural de la seva història. Fins a 1945, Espanya no era qualitativament diferent del seu entorn europeu, tot i la Guerra Civil i del seu resultat; sí que ho 
era, però, quantitativament. Podríem dir que Espanya era la versió low cost d'un Estat-nació burgès europeu. Com els avions d'aquestes companyies, tenia tots els elements necessaris per funcionar, però en la versió més devaluada. Si algun àmbit il.lustra la metàfora és l'educació.

Espanya bastí al segle xix un sistema nacional d'educació elitista, classista, patriarcal i homòfob, i precisament per això era prototípic del món burgès occidental. Tan prototípic que alguns, com Itàlia, es copiaven tota l'estona d'un model que era al seu torn una còpia de França. No hi havia res qualitativament diferent en el model espanyol, sinó una permanent devaluació quantitativa: un finançament paupèrrim, poques escoles i instituts, un batxillerat més curt ... tot al mínim i fins i tot per sota, especialment quan els liberals plegaren veles en la seva batalla amb la Església per la construcció del sistema nacional després de la Restauració borbònica i l'Estat s'inhibí fins i tot de complir la seva pròpia llei. Fou llavors, a finals del segle xix, quan Espanya començà a separar-se del seu entorn en matèria educativa. Però la cosa encara no era dramàtica. Com a conseqüència del desastre, a principis de segle $x x$, els polítics monàrquics reaccionaren $i$ dissenyaren un programa de modernització coherent i ben pensat, compartit per conservadors i liberals, en un primer moment, i progressivament desplaçat cap al camp progressista integrant a republicans, socialistes i fins i tot més enllà com a conseqüència de la creixent desafecció de camp conservador, cada vegada més influït per una Església que vivia qualsevol avanç en el sistema públic com una agressió intolerable als seus drets.

Però tot i la desconfiança conservadora, el programa es mantingué incòlume al llarg de tres dècades i tres règims tan diferents com la monarquia constitucional, la dictadura de Primo de Rivera i la Segona
República. En veritat, la República no inventà res en educació, simplement se la prengué seriosament, cosa que en aquest país ja és molt, tant que ens va costar una guerra. La República senzillament es posà mans a l'obra i intensificà la política de creació de noves escoles i nous instituts que havia iniciat la Dictadura de Primo, política que li va costar la retirada del suport de l'Església i en última instància el seu fracàs.

I llavors va arribar el franquisme, l'àngel exterminador. Aparentment la política educativa franquista fou el negatiu de la República. Allà on la República deia blanc el règim corregia negre: enfront del laïcisme, recristianització, enfront de la professionalització del magisteri, ideologització extrema, enfront de l'europeïtzació, immersió imperial, etc. Tot això és ben conegut, però constitueix només la manifestació epidèrmica d'una rectificació molt més radical i profunda. No es pretenia retornar a l'abril de 1931, sinó molt més enrere, per descomptat abans de 1900, però per una part significativa abans de la Constitució de Cadis i fins i tot del reformisme borbònic del segle xviii. Els vencedors en la guerra civil plantejaren una esmena a la totalitat als moderns sistemes educatius, aquell monstre del qual les esglésies desconfiaven i contra el qual Església espanyola portava lluitant sense descans des de feia més de dos segles. S'havia guanyat una guerra; era el moment de treballar durament sense vacil.lacions ni contemplacions.

No hi ha referent internacional per a la política educativa del franquisme, ni a Itàlia, ni a Alemanya, ni tan sols a Àustria o Portugal; fou un veritable deliri de tremendes conseqüències. Per posar en pràctica la seva utopia reaccionària, el franquisme no dubtà a dilapidar la inversió realitzada durant gairebé quatre dècades en capital humà, tota l'ingent tasca de millora del personal docent i científic realitzada sota 
I'ideal regeneracionista. Tot per la borda; en realitat, tots en vaixells cap a Llatinoamèrica, quan no a la presó o a la fossa comuna. No existeix àmbit educatiu, científic o cultural on no es constati aquesta neteja radical. 1939 fou en veritat un any zero que deixà un erm. Començà, aleshores, la llarga nit de l'educació espanyola; aquells anys terribles, freds i foscos, de fam, por i misèria, en els que als espanyols no se'ls permeté ni l'evasió del cinema, perquè abans de passar-s'ho bé amb Imperio Argentina o Estrellita Castro, que ja eren règim en versió edulcorada, havien d'empassar-se primer sense aigua la píndola de l'adoctrinament dur del NO-DO, I'única educació en la qual el franquisme semblava interessat i que estudia aquest llibre.

És clar que a finals dels cinquanta el propi règim prengué consciència que $\mathrm{amb}$ aquest model educatiu no anava enlloc, que estava fora del temps i de l'espai. Calia industrialitzar el país per salvar el règim i per a això no quedava una altra que recuperar el temps perdut a marxes forçades, fins i tot a costa de copiar les nefandes mesures republicanes per expandir el sistema educatiu, i acabar per aprovar una llei revolucionària com LGE de 1970. No obstant això, el mal ja estava fet i no havia de resultar fàcil reparar dues dècades de destrossa sistemàtica ni recuperar el capital humà malbaratat.

El lector pot estar o no d'acord amb aquesta tesi, però aquest desacord constitueix en sí mateix la prova de què l'educació sota el franquisme suscita qüestions de calat historiogràfic. Per això no pot deixar celebrar-se la publicació d'un llibre com aquest i resulta obligatori felicitar els seus autors i encoratjar-los a què perseverin en aquest camí. 